\title{
Atherosclerotic coronary artery disease: The accuracy of measures to diagnose preclinical atherosclerosis
}

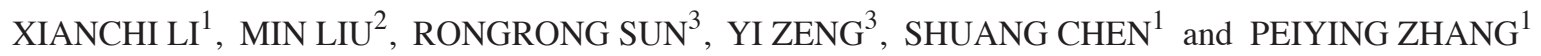 \\ ${ }^{1}$ Department of Cardiology, The Affiliated Xuzhou Hospital of Medical College of Southeast University; \\ ${ }^{2}$ Department of Cardiology, Xuzhou Clinical School of Xuzhou Medical College; ${ }^{3}$ Xuzhou Clinical Medical College \\ of Nanjing University of Chinese Medicine, Xuzhou, Jiangsu 221009, P.R. China
}

Received March 15, 2016; Accepted September 12, 2016

DOI: $10.3892 / \mathrm{etm} .2016 .3710$

\begin{abstract}
Different methods can be used to diagnose early pre-clinical stage atherosclerosis. The present study was carried out to evaluate the efficiency of these methods. Measures including carotid intima-media thickness (CIMT), pulse wave velocity (PWV), and coronary calcium score (CCS) were evalutated for the detection of coronary artery disease (CAD). We studied the clinical and biochemical profiles of individuals with non-CAD and CAD to assess measures of pre-clinical atherosclerosis. The association between CIMT, PWV and CCS on the one hand, and the coronary atherosclerosis on the other, was studied. In total, 150 cases of cardiovascular disease (CVD) participated in the present study and were subjected to computed tomographic (CT) coronary angiography to divide them into non-CAD $(n=100)$ and CAD $(n=50)$ groups. The patients were also subjected to pre-clinical atherosclerosis tests (CIMT, PWV and CCS). CAD patients had higher CIMT values on both sides (right side, $0.74 \pm 0.09$ vs. $0.62 \pm 0.12 \mathrm{~mm}$; left side, $0.78 \pm 0.16$ vs. $0.64 \pm 0.19 \mathrm{~mm}$; and average, $0.76 \pm 0.12$ vs. $0.63 \pm 0.14 \mathrm{~mm}$; all P-values $<0.01)$. These patients also had significantly higher brachial-ankle PWV (baPWV) on left side (1638.8 \pm 372.9 vs. $1498.6 \pm 339.8 \mathrm{~cm} / \mathrm{sec}, \mathrm{P}<0.001)$. The overall CCS was significantly increased in CAD patients as compared to the patients without CAD $(117.8 \pm 118.6$ vs. $8.6 \pm 18.3, \mathrm{P}<0.001)$. In conclusion, the present study showed that among different measures of preclinical atherosclerosis, CCS had the best diagnostic accuracy. However, the combination of CIMT and baPWV had an excellent negative predictive value for atherosclerotic coronary vascular disease.
\end{abstract}

Correspondence to: Dr Peiying Zhang, Department of Cardiology, The Affiliated Xuzhou Hospital of Medical College of Southeast University, 199 Jiefang Road, Xuzhou, Jiangsu 221009, P.R. China E-mail: zpying58@126.com

Key words: carotid intima media thickness, coronary calcium score, cardiovascular disease, hypertension, pulse wave velocity

\section{Introduction}

Early detection of atherosclerosis in its pre-clinical stage has emerged as a promising approach to facilitate optimum cardiovascular (CV) risk stratification in asymptomatic individuals (1-4). Although definitive outcome data is absent, preliminary evidence suggested that addition of atherosclerosis imaging to conventional risk assessment tools may help us to achieve a better understanding about the nature and the aggressiveness of the preventive measures and can thus improve the clinical outcomes (5). There is scarce evidence suggesting that detection of structural evidence of atherosclerosis may improve patient compliance toward therapeutic measures (6-10). The endothelium has an important role in maintaining vascular homeostasis $(3,4)$. Endothelial function can be measured in a variety of ways using invasive and non-invasive techniques in the coronary and peripheral circulation. The clinical examination of endothelial function involves assessing its ability to release NO in response to various exogenous and endogenous stimuli (11). Evaluation of reproducible, non-invasive techniques for assessing endothelial function should enable us to screen large populations and may guide us to design methods to reduce the individual's vascular risk.

Numerous tools have been developed for pre-clinical atherosclerosis assessments. This list includes carotid intima-media thickness (CIMT), brachial artery flow-mediated dilatation, pulse wave velocity (PWV) and coronary calcium score (CCS). Although these techniques can detect one or more atherosclerotic indicators, they have substantial methodological differences that are responsible for the differences in their availability, cost, ease of use, repeatability, and radiation exposure. Given these differences, it is imperative to determine their relative diagnostic accuracy in order to be able to accurately define their role in routine clinical practice. Although studies conducted in western populations suggested that CCS had the best predictive accuracy $(12,13)$, few studies have compared different modalities of pre-clinical atherosclerosis detection in the Indian populations (14).

The present study was conducted to compare the strength of three commonly used and approved measures of pre-clinical atherosclerosis assessment methods, namely CIMT, PWV and CCS. In this study we evaluated the clinical and biochemical profiles of non-coronary artery disease (CAD) and CAD cases. 
We also verified the association of CIMT, PWV and CCS with coronary atherosclerosis.

\section{Patients and methods}

A total of 150 cases were recruited and participated in this study (irrespective to previous history of cardiovascular disease). Patients were divided into two groups: The non-CAD group, including those without any evidence of atherosclerotic coronary vascular disease $(n=100)$ and the CAD group, which included patients with evidence of atherosclerotic coronary vascular disease $(n=50)$. Patients were included in non-CAD group if they met all the following criteria: i) No previous history of documented CAD; ii) no atherosclerotic plaque seen on conventional or computed tomographic (CT) coronary angiography.

In contrast, the patients were assigned to CAD group if any of the following conditions was present: i) Any previous history of documented CAD, with or without coronary revascularization; ii) coronary angiography (conventional or CT) showing evidence of significant CAD defined as $>50 \%$ luminal narrowing involving at least one epicardial coronary artery; or iii) evidence of coronary plaques, even with less significant luminal obstruction $(<50 \%)$, on conventional or CT coronary angiography.

All cases underwent clinical evaluation, biochemical tests and assessment of pre-clinical atherosclerosis. Clinical evaluation included detailed history regarding the presence or absence of $\mathrm{CV}$ risk factors, duration of $\mathrm{CV}$ risk factors, and use of statins. Physical examination included height, weight and blood pressure measurement and the examination of $\mathrm{CV}$ system. Blood pressure was measured in the right arm in supine position, using a standard sphygmomanometer. Biochemical tests included fasting and 2-h postprandial blood glucose measurements, fasting lipid profile and the measurement of high-sensitivity C-reactive protein (hsCRP). Pre-clinical atherosclerosis assessment included CIMT measurement, PWV assessment and CCS estimation.

HT was defined according to Joint National Committee (JNC) 7 guidelines as systolic $\mathrm{BP} \geq 140 \mathrm{mmHg}$ or diastolic BP $\geq 90 \mathrm{mmHg}$ or previous history of HT or self-reported use of anti-hypertensive medications (15). Diabetes mellitus was defined as fasting blood glucose $>126 \mathrm{mg} / \mathrm{dl}$ or $2-\mathrm{h}$ postprandial blood glucose $>200 \mathrm{mg} / \mathrm{dl}$ or pharmacological treatment for diabetes or previous history of diabetes mellitus. Family history was considered positive if a coronary event had occurred in a male first-degree relative before the age of 55 years or a female first-degree relative before the age of 65 years. Smoking or tobacco use in any form during the preceding month was also considered to be a CV risk factor.

CIMT assessment. For CIMT measurement, distal common carotid artery (CCA) was imaged on both sides with a 7.5 $\mathrm{MHz}$ frequency linear array transducer, attached to any standard vascular ultrasound machine. The artery was imaged in a longitudinal plane to obtain optimal angle of incidence, defined as the plane in which the bifurcation of the carotid bulb into the internal and external carotid arteries can be visualized simultaneously with the bulb and distal CCA (also known as 'tuning fork'). Once this view was obtained, finer adjustments in the transducer position was done to make sure that distal CCA was perfectly horizontal on the screen and 'double lines' of intima and adventitia were clearly visualized in the far wall of the CCA ('double-line' sign). From this view, the CIMT was measured as the distance between lumen-intima interface and the media-adventitia interface. Plaques, defined as $>50 \%$ localized thickening of the intima compared to the rest of the wall, were included in the measurement of CIMT if present within the distal $1 \mathrm{~cm}$ of CCA.

The CCA was then imaged from two additional complimentary angles, approximately $45^{\circ}$ anterior and posterior to the first image and the CIMT measurements were performed. The three values thus obtained for each side were averaged and used for analysis. Reproducibility of CIMT measurement in our lab was documented (16).

$P W V$ measurement. Measurement of PWV was performed using the PeriScope ${ }^{\circledR}$ device (Genesis Medical Systems Pvt. Ltd., Hyderabad, India) which was shown to have high degree of reproducibility for this purpose (17). This device was based on oscillometric method and records arterial pressure waveforms noninvasively. ECG-gated pressure waveforms were recorded simultaneously from both arms and both ankles. From these pressure waveforms, in-built software automatically calculates PWV for different vascular segments (18).

The procedure was performed during the morning hours, after overnight fast for $10 \mathrm{~h}$. Participants were asked to refrain from smoking for at least $4 \mathrm{~h}$ before the procedure. On going medications were not discontinued but the morning dose was delayed until completion of the test. The procedure was performed in supine position. After $10 \mathrm{~min}$ of supine rest, four BP cuffs, which were connected to the PeriScope ${ }^{\circledR}$ device, were tied around both arms and both ankles. These BP cuffs carried oscillometric sensors to record pressure waveforms from the underlying arteries. ECG electrodes were put on the wrists and ankles to record ECG simultaneously. The machine then automatically inflated and deflated the cuffs simultaneously, while recording pressure waveforms from the four sites. From these pressure waveforms, right and left brachial-ankle PWV (baPWV) were calculated and used for analysis.

Coronary calcium scoring. Heart multidetector CT was performed using dual-source dual-energy Somatom Definition Flash (Siemens Healthcare, Erlangen, Germany) with $128 \times 0.6 \mathrm{~mm}$ collimation, rotation time $75 \mathrm{msec}$ and tube voltage of 80 and $140 \mathrm{kV}$. In single breath-hold, images were taken from the tracheal bifurcation level to the base of the heart using prospective ECG triggering with the center of the acquisition at $70 \%$ of the R-R interval. From the raw data, the images were reconstructed with standard kernel in 3-mm thick axial, non-overlapping slices and $25 \mathrm{~cm}$ field of view. All image analyses were performed on a dedicated workstation (MMWP and syngo.via; Siemens Healthcare). A coronary calcified lesion was defined as an area with a density $>130$ Hounsfield units and covering at least 6 pixels. The Agatston method was used to determine the CCS by multiplying each lesion area by a weighted CT attenuation score in the lesion (19).

Statistical analysis. The data analysis was done in line with study objectives. Statistical analyses were performed using 
SPSS version 16.0. Values were expressed as mean \pm standard deviation or as percentages. Comparisons between the groups were carried out using Student's unpaired t-test or Chi-square test as appropriate. A P-value of 0.05 was considered to indicate a statistically significant difference.

\section{Results}

Patients in the non-CAD group were older $(62.9 \pm 3.2$ vs. $39.6 \pm 8.2$ years, $\mathrm{P}<0.001)$ than those in the $\mathrm{CAD}$ group. However, there was no significant difference between the two groups in terms of hypertension, diabetes, smoking and family history of premature CAD. The two groups did not show any significant difference in body mass index, systolic or diastolic blood pressure or hsCRP. However, as expected, the CAD patients were more likely to be on statin therapy (84.0 vs. $34.0 \%, \mathrm{P}<0.001$ ) which probably accounted for their lower total cholesterol, low-density lipoprotein cholesterol and triglyceride levels (Table I).

CAD patients had increased CIMT values on both sides (right side, $0.74 \pm 0.09$ vs. $0.62 \pm 0.12 \mathrm{~mm}$; left side, $0.78 \pm 0.16$ vs. $0.64 \pm 0.19 \mathrm{~mm}$; and average, $0.76 \pm 0.12$ vs. $0.63 \pm 0.14 \mathrm{~mm}$; all P-values $<0.01)$. These patients also had significantly higher baPWV on the left side $(1638.8 \pm 372.9$ vs. $1498.6 \pm 339.8 \mathrm{~cm} /$ sec, $\mathrm{P}<0.001)$. The overall CCS was significantly higher in CAD patients when compared to the patients in the non-CAD group $(117.8 \pm 118.6$ vs. $8.6 \pm 18.3, \mathrm{P}<0.001)$ however, there were no significant differences in right side baPWV or the average of the two (Table II).

\section{Discussion}

Over the past few decades, atherosclerotic cardiovascular disease (CVD) has become the leading cause of death worldwide. The rapid increase in the incidence and prevalence of CVD has led to a growing recognition of the need to develop and implement effective strategies for its prevention. Raising awareness to CVD risk and the role of healthy life-style appears to be the most effective strategy for CVD prevention. Nevertheless, these efforts have been greatly limited by negligence and general apathy amongst public toward the healthy life-style measures. A more effective strategy may be to identify 'high-risk' individuals and focus all efforts and resources to prevent the development of disease in this group. Presently, CV risk assessment is generally performed using conventional $\mathrm{CV}$ risk factors and risk algorithms such as Framingham risk score. Several studies have shown that although these risk algorithms perform reasonably well at the population level, their accuracy at the individual level is rather dismal (20-23). Frequently we find individuals with multiple $\mathrm{CV}$ risk factors and high estimated $\mathrm{CV}$ risk who do not necessarily develop clinical CVD even in the long term, whereas there are other patients who present with acute $\mathrm{CV}$ event despite being free of all known major $\mathrm{CV}$ risk factors. To overcome this limitation, several diagnostic tools with the capability of detecting atherosclerotic vascular disease in early, pre-clinical stages have been developed recently. These tools can provide direct evidence on ongoing atherosclerotic process, irrespective of the presence or absence of known $\mathrm{CV}$ risk factors. Numerous large-scale studies have unequivocally
Table I. Clinical and biochemical characteristics of patients in both groups.

\begin{tabular}{|c|c|c|c|}
\hline Parameters & $\begin{array}{c}\text { Non-CAD } \\
\text { group }(\mathrm{n}=100)\end{array}$ & $\begin{array}{l}\text { CAD group } \\
\quad(\mathrm{n}=50)\end{array}$ & P-value \\
\hline Age (years) & $39.6 \pm 8.2$ & $62.9 \pm 3.2$ & $<0.001$ \\
\hline Gender (Male) & $78(78.0 \%)$ & $42(84.0 \%)$ & 0.64 \\
\hline Hypertension & $76(76.0 \%)$ & $42(84.0 \%)$ & 0.06 \\
\hline Diabetes mellitus & $15(15.0 \%)$ & $25(50.0 \%)$ & 0.003 \\
\hline $\begin{array}{l}\text { Family history of } \\
\text { premature coronary } \\
\text { artery disease }\end{array}$ & $48(48.0 \%)$ & $35(70.0 \%)$ & 0.01 \\
\hline Current smoking & $39(39.0 \%)$ & $23(46.0 \%)$ & 0.08 \\
\hline Statin use & $34(34.0 \%)$ & $42(84.0 \%)$ & 0.001 \\
\hline Total cholesterol (mg/dl) & $192.0 \pm 32.6$ & $168.0 \pm 25.2$ & $<0.001$ \\
\hline HDL-cholesterol (mg/dl) & $42.0 \pm 11.3$ & $40.4 \pm 10.5$ & 0.31 \\
\hline LDL-cholesterol (mg/dl) & $108.5 \pm 23.1$ & $84.2 \pm 27.4$ & $<0.001$ \\
\hline Triglycerides (mg/dl) & $162.6 \pm 35.0$ & $132.9 \pm 41.8$ & 0.002 \\
\hline Body mass index $\left(\mathrm{kg} / \mathrm{m}^{2}\right)$ & $29.2 \pm 2.1$ & $28.3 \pm 2.8$ & 0.48 \\
\hline $\begin{array}{l}\text { Systolic blood } \\
\text { pressure }(\mathrm{mmHg})\end{array}$ & $134.4 \pm 9.6$ & $131.9 \pm 10.2$ & 0.77 \\
\hline $\begin{array}{l}\text { Diastolic blood } \\
\text { pressure }(\mathrm{mmHg})\end{array}$ & $82.5 \pm 6.5$ & $84.8 \pm 6.9$ & 0.26 \\
\hline $\begin{array}{l}\text { Fasting blood } \\
\text { glucose }(\mathrm{mg} / \mathrm{dl})\end{array}$ & $104.3 \pm 25.7$ & $112.4 \pm 31.7$ & 0.09 \\
\hline hsCRP (mg/dl) & $3.1 \pm 5.0$ & $5.4 \pm 4.6$ & 0.25 \\
\hline
\end{tabular}

CAD, coronary artery disease; hsCRP, high-sensitivity C-reactive protein.

Table II. Pre-clinical atherosclerosis in patients in both groups.

\begin{tabular}{lccc}
\hline Parameter & $\begin{array}{c}\text { Non-CAD } \\
\text { group }(\mathrm{n}=100)\end{array}$ & $\begin{array}{c}\text { CAD group } \\
(\mathrm{n}=50)\end{array}$ & P-value \\
\hline CIMT (mm) & & & \\
Right side & $0.62 \pm 0.12$ & $0.74 \pm 0.09$ & 0.008 \\
Left side & $0.64 \pm 0.19$ & $0.78 \pm 0.16$ & 0.005 \\
Average & $0.63 \pm 0.14$ & $0.76 \pm 0.12$ & 0.003 \\
Pulse wave velocity & & & \\
(cm/sec) & & & \\
Right brachial-ankle & $1632.0 \pm 376.5$ & $1584.6 \pm 325.6$ & 0.51 \\
Left brachial-ankle & $1498.6 \pm 339.8$ & $1638.8 \pm 372.9$ & $<0.001$ \\
Average brachial-ankle & $1518.2 \pm 323.0$ & $1589.2 \pm 307.7$ & 0.58 \\
CCS & $8.6 \pm 18.3$ & $117.8 \pm 118.6<0.001$
\end{tabular}

CAD, coronary artery disease; CIMT, carotid intima-media thickness; CCS, coronary calcium score.

demonstrated the incremental value of such techniques over conventional $\mathrm{CV}$ risk factors in prediction of future $\mathrm{CV}$ risk $(4,18,24)$. The benefits of the incorporation of these diagnostic techniques into the standard risk assessment approach is still unclear, however existing evidence suggests that such a strategy can be very helpful. It can help us to 
have a better understanding about the nature, timing and aggressiveness of anti-atherosclerotic therapy. Also it can help us in improving patient's compliance toward these measures and may aid in monitoring the response to therapy (1,2,4-10).

CIMT, brachial artery flow-mediated dilatation, PWV assessment, ankle-brachial index and CCS are the most commonly used pre-clinical atherosclerosis measures. All these tools are used to detect evidence of atherosclerosis in different vascular beds with the underlying rationale that atherosclerosis is a generalized disease and its presence in one vascular bed indirectly implies involvement, though not necessarily concurrently, also of other vascular beds. However, these techniques are methodologically vastly different from each other and therefore have significant differences in their availability, cost, ease of use, repeatability, and radiation exposure. As many of these techniques are already available for clinical use, it is important to determine their relative diagnostic accuracy in order to allow for their judicious, cost-effective and meaningful use in routine clinical practice.

In conclusion, the present study shows that among different measures of pre-clinical atherosclerosis, CCS is the most accurate diagnostic tool for the detection of coronary atherosclerosis. However, the combination of CIMT and baPWV has an excellent negative predictive value for atherosclerotic coronary vascular disease and can therefore be used as a simple, non-invasive, less expensive and radiation-free approach to initial CV risk stratification. Those with abnormal CIMT or baPWV can subsequently be subjected to CCS for further refinement of their $\mathrm{CV}$ risk.

\section{References}

1. Greenland P, Alpert JS, Beller GA, Benjamin EJ, Budoff MJ, Fayad ZA, Foster E, Hlatky MA, Hodgson JM, Kushner FG, et al; American College of Cardiology Foundation; American Heart Association: 2010 ACCF/AHA guideline for assessment of cardiovascular risk in asymptomatic adults: a report of the American College of Cardiology Foundation/American Heart Association Task Force on Practice Guidelines. J Am Coll Cardiol 56: e50-e103, 2010.

2. Mancia G, De Backer G, Dominiczak A, Cifkova R, Fagard R, Germano G, Grassi G, Heagerty AM, Kjeldsen SE, Laurent S, et al; The task force for the management of arterial hypertension of the European Society of Hypertension; The task force for the management of arterial hypertension of the European Society of Cardiology: 2007 guidelines for the management of arterial hypertension: the task force for the management of arterial hypertension of the european society of hypertension (esh) and of the european society of cardiology (ESC). Eur Heart J 28: 1462-1536, 2007.

3. Can atherosclerosis imaging techniques improve the detection of patients at risk for ischemic heart disease? Proceedings of the 34th Bethesda Conference. Bethesda, Maryland, USA. October 7, 2002. J Am Coll Cardiol 41: 1856-1917, 2003

4. Stein JH, Korcarz CE, Hurst RT, Lonn E, Kendall CB, Mohler ER Najjar SS, Rembold CM and Post WS; American Society of Echocardiography Carotid Intima-Media Thickness Task Force Endorsed by the Society for Vascular Medicine: Use of carotid ultrasound to identify subclinical vascular disease and evaluate cardiovascular disease risk: a consensus statement from the American Society of Echocardiography Carotid Intima-Media Thickness Task Force. J Am Soc Echocardiogr 21: 93-111, quiz 189-190, 2008.

5. Shah PK: Screening asymptomatic subjects for subclinical atherosclerosis: can we, does it matter, and should we? J Am Coll Cardiol 56: 98-105, 2010.

6. Bovet P, Perret F, Cornuz J, Quilindo J and Paccaud F: Improved smoking cessation in smokers given ultrasound photographs of their own atherosclerotic plaques. Prev Med 34: 215-220, 2002.

7. Wyman RA, Gimelli G, McBride PE, Korcarz CE and Stein JH: Does detection of carotid plaque affect physician behavior or motivate patients? Am Heart J 154: 1072-1077, 2007.
8. Barth JD: Which tools are in your cardiac workshop? Carotid ultrasound, endothelial function, and magnetic resonance imaging. Am J Cardiol 87 (4A): 8A-14A, 2001.

9. Kalia NK, Miller LG, Nasir K, Blumenthal RS, Agrawal N and Budoff MJ: Visualizing coronary calcium is associated with improvements in adherence to statin therapy. Atherosclerosis 185: 394-399, 2006

10. Taylor AJ, Bindeman J, Feuerstein I, Le T, Bauer K, Byrd C, Wu H and O'Malley PG: Community-based provision of statin and aspirin after the detection of coronary artery calcium within a community-based screening cohort. J Am Coll Cardiol 51: $1337-1341,2008$.

11. Ludmer PL, Selwyn AP, Shook TL, Wayne RR, Mudge GH, Alexander RW and Ganz P: Paradoxical vasoconstriction induced by acetylcholine in atherosclerotic coronary arteries. $\mathrm{N}$ Engl J Med 315: 1046-1051, 1986.

12. Folsom AR, Kronmal RA, Detrano RC, O'Leary DH, Bild DE, Bluemke DA, Budoff MJ, Liu K, Shea S, Szklo M, et al: Coronary artery calcification compared with carotid intima-media thickness in the prediction of cardiovascular disease incidence: The Multi-Ethnic Study of Atherosclerosis (MESA). Arch Intern Med 168: 1333-1339, 2008.

13. Simon A, Chironi G and Levenson J: Comparative performance of subclinical atherosclerosis tests in predicting coronary heart disease in asymptomatic individuals. Eur Heart J 28: 2967-2971, 2007.

14. Kasliwal RR, Bansal M, Bhargava K, Gupta H, Tandon S and Agrawal V: Carotid intima-media thickness and brachial-ankle pulse wave velocity in patients with and without coronary artery disease. Indian Heart J 56: 117-122, 2004.

15. Chobanian AV, Bakris GL, Black HR, Cushman WC, Green LA, Izzo JL Jr, Jones DW, Materson BJ, Oparil S, Wright JT Jr, et al; National High Blood Pressure Education Program Coordinating Committee: The seventh report of the joint national committee on prevention, detection, evaluation, and treatment of high blood pressure: the JNC 7 report. JAMA 289: 2560-2572, 2003.

16. Kasliwal RR, Agrawal S and Bansal M: Carotid intima-media thickness and brachial artery flow-mediated dilatation in patients with and without metabolic syndrome. Indian Heart J 58: 42-46, 2006.

17. Naidu MU, Reddy BM, Yashmaina S, Patnaik AN and Rani PU: Validity and reproducibility of arterial pulse wave velocity measurement using new device with oscillometric technique: a pilot study. Biomed Eng Online 4: 49, 2005.

18. Laurent S, Cockcroft J, Van Bortel L, Boutouyrie P, Giannattasio C, Hayoz D, Pannier B, Vlachopoulos C, Wilkinson I and Struijker-Boudier H; European Network for Non-invasive Investigation of Large Arteries: Expert consensus document on arterial stiffness: methodological issues and clinical applications. Eur Heart J 27: 2588-2605, 2006.

19. Agatston AS, Janowitz WR, Hildner FJ, Zusmer NR, Viamonte M Jr and Detrano R: Quantification of coronary artery calcium using ultrafast computed tomography. J Am Coll Cardiol 15: 827-832, 1990.

20. Nasir K, Michos ED, Blumenthal RS and Raggi P: Detection of high-risk young adults and women by coronary calcium and National Cholesterol Education Program Panel III guidelines. J Am Coll Cardiol 46: 1931-1936, 2005.

21. Lauer MS: Primary prevention of atherosclerotic cardiovascular disease: the high public burden of low individual risk. JAMA 297: 1376-1378, 2007.

22. Shaw LJ, Blumenthal RS and Raggi P: Screening asymptomatic low-risk individuals for coronary heart disease: issues and controversies. J Nucl Cardiol 11: 382-387, 2004.

23. Akosah KO, Schaper A, Cogbill C and Schoenfeld P: Preventing myocardial infarction in the young adult in the first place: how do the National Cholesterol Education Panel III guidelines perform? J Am Coll Cardiol 41: 1475-1479, 2003.

24. Greenland P, Bonow RO, Brundage BH, Budoff MJ, Eisenberg MJ, Grundy SM, Lauer MS, Post WS, Raggi P, Redberg RF, et al; American College of Cardiology Foundation Clinical Expert Consensus Task Force (ACCF/AHA Writing Committee to Update the 2000 Expert Consensus Document on Electron Beam Computed Tomography); Society of Atherosclerosis Imaging and Prevention; Society of Cardiovascular Computed Tomography: ACCF/AHA 2007 clinical expert consensus document on coronary artery calcium scoring by computed tomography in global cardiovascular risk assessment and in evaluation of patients with chest pain: a report of the American College of Cardiology Foundation Clinical Expert Consensus Task Force (ACCF/AHA Writing Committee to Update the 2000 Expert Consensus Document on Electron Beam Computed Tomography) developed in collaboration with the Society of Atherosclerosis Imaging and Prevention and the Society of Cardiovascular Computed Tomography. J Am Coll Cardiol 49: 378-402, 2007. 